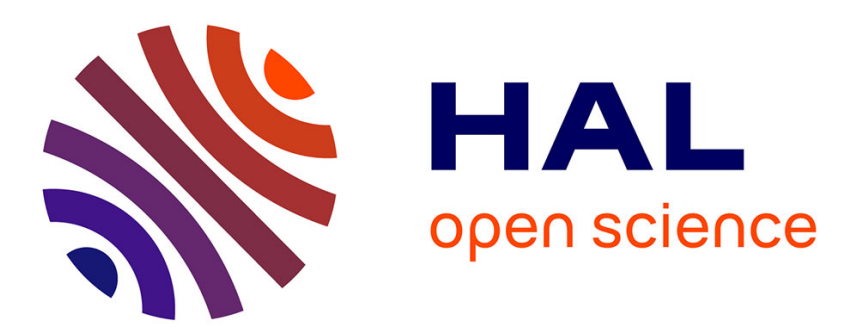

\title{
Determination of the CO2 and N2 dilution influence on flame flashback limits of methane and propane combustible mixtures
}

\author{
Maria Clara de Jesus Vieira, Luis Fernando Figueira da Silva
}

\section{To cite this version:}

Maria Clara de Jesus Vieira, Luis Fernando Figueira da Silva. Determination of the CO2 and N2 dilution influence on flame flashback limits of methane and propane combustible mixtures. 18th Brazilian Congress of Thermal Sciences and Engineering, Nov 2020, online, Brazil. 10.26678/ABCM.ENCIT2020.CIT20-0157 . hal-03357888

\author{
HAL Id: hal-03357888 \\ https://hal.science/hal-03357888
}

Submitted on 29 Sep 2021

HAL is a multi-disciplinary open access archive for the deposit and dissemination of scientific research documents, whether they are published or not. The documents may come from teaching and research institutions in France or abroad, or from public or private research centers.
L'archive ouverte pluridisciplinaire HAL, est destinée au dépôt et à la diffusion de documents scientifiques de niveau recherche, publiés ou non, émanant des établissements d'enseignement et de recherche français ou étrangers, des laboratoires publics ou privés. 


\title{
ENC-2020-0157 \\ Determination of the $\mathrm{CO}_{2}$ and $\mathrm{N}_{2}$ dilution influence on flame flashback limits of methane and propane combustible mixtures
}

\author{
Maria Clara de Jesus Vieira \\ Luís Fernando Figueira da Silva \\ Department of Mechanical Engineering \\ Pontifícia Universidade Católica do Rio de Janeiro \\ Rua Marquês de São Vicente, 225 \\ 22.451-900 Rio de Janeiro, RJ BRAZIL \\ mariaclarajvieira@puc-rio.br, luisfer@puc-rio.br
}

Abstract. The flashback phenomenon in tubes has been known and studied for several decades. The classical analysis of this phenomenon is based on the determination of a critical velocity gradient that delimits the boundaries of flame flashback as a function of the mixture properties. However, significant knowledge gaps remain, particularly with regard to the effect of $\mathrm{CO}_{2}$ dilution, which is important for predicting the safety of Brazilian pre-salt facilities. Accordingly, the general objective of this work is to experimentally determine the influence of $\mathrm{CO}_{2}$ dilution on the flame flashback of gaseous air/hydrocarbon mixtures. In particular, the critical velocity gradient was determined for $\mathrm{CH}_{4} /$ air mixtures with $\mathrm{CO}_{2}$-diluted fuel (0, 10 and 30\%). For comparison purposes, measurements were also performed on propane/air mixtures diluted by $\mathrm{CO}_{2}$ or by $\mathrm{N}_{2}$. For both diluent species, a reduction in the maximum value of the critical velocity gradient was observed with the increase of the dilution. Such as behavior was associated to the corresponding decrease with dilution of the laminar flame speed, which was computed using two chemical kinetics models.

Keywords: Premixed flame, Flame flashback, Critical velocity gradient, Experimental study

\section{INTRODUCTION}

This study is motivated by the need to have reliable correlations and models capable of predicting a possible flame flashback when burning the gas excess produced in the Brazilian pre-salt reservoirs. Since the composition of the combustible gases produced in those wells differs significantly from that found in other reservoirs, in particular due to the presence of $\mathrm{CO}_{2}$ (ANP, 2020), the models that may be found in the literature for this phenomenon are outside their range of application.

In recent years, flame flashback studies have dealt mainly with the phenomena associated with combustion in gas turbines. This is due to the development of new pre-mixed combustors with low NOx emissions. In pre-mixed gas turbine combustion chambers, flame flashback may occur as a result of four mechanisms: core flow flashback, combustion instability induced flashback and boundary layer flashback (Kalantari and McDonell, 2017).

The boundary layer flashback is considered the primary flame flashback mechanism of interest to the present study. This mechanism is relevant, in particular, in gas turbines operating under normal conditions, that is, when the pre-mixer's free flow velocity exceeds that of the turbulent flame. As a result, flame propagation cannot occur in the core region. However, the flow velocity decreases close to the wall, which may lead to flame flashback. It is believed that this mechanism is the one that determines the critical conditions leading to the flame flashback in tubes. In fact, even in physical situations where the premixed flame is stabilized in a turbulent flow, in the vicinity of the walls the boundary layer exhibits a laminar sublayer. This low-velocity region could allow the propagation, from downstream to upstream, of flames. For this reason, the boundary layer flashback is the one studied in this project.

Classically (Lewis and von Elbe, 1949), the boundary layer flashback is assumed to occur when the flow velocity is smaller than the burning velocity at some point near the tube wall. The critical velocity gradient $\left(G_{c}\right)$ is an often used parameter to characterize this flashback mechanism. This model strong assumption is that there is no flame/fluid interaction and, thus, no disturbances in the flow velocity. Accordingly, Fig. 1 shows the schematic model used to describe the critical velocity gradient, where a stabilized flame front can be seen inside a tube, near the wall.

In Fig. 1, the flow velocity [which average is $\bar{U}=\forall_{t} /\left(\pi R^{2}\right), \forall_{t}$ being the mixture flow rate and $R=D / 2$ the tube radius] is represented by a parabolic profile, which is consistent with the flashback onset within circular tubes where laminar flow occurs at the wall vicinity. Furthermore, the position in which the burning velocity $\left(S_{L}\right.$, the laminar flame front speed) is equal to the flow velocity is defined as the penetration distance $\left(\delta_{p}\right)$. In this flashback model, the laminar flame front velocity is the velocity with which the adiabatic, isobaric and flat flame propagates, freely from the burnt 

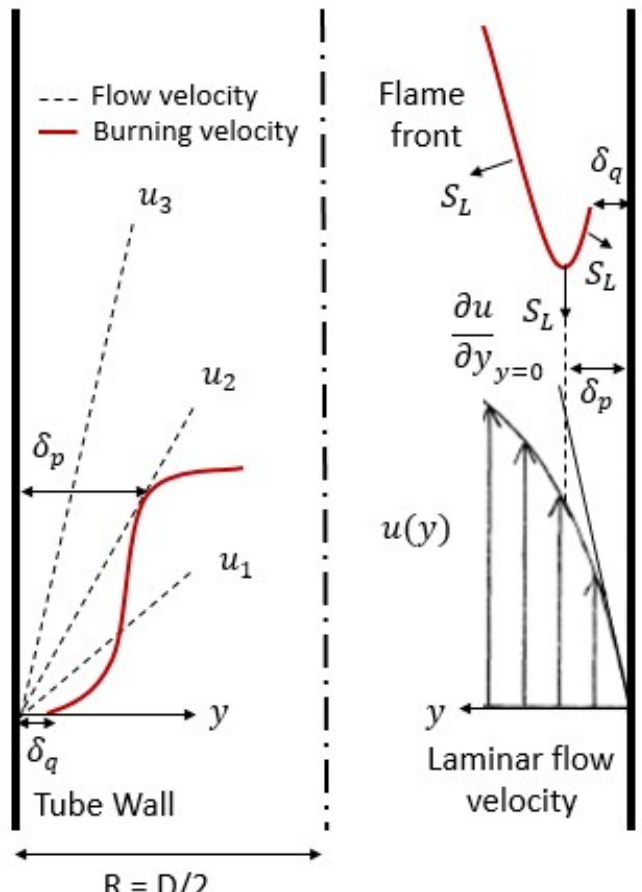

Figure 1: Boundary layer flashback schemes, leading to the critical velocity gradient concept.

gases to the fresh gases, $S_{L}$ (Law, 2006), that is a property of the combustible mixture. According to the theory developed by Mallard and Le Chatelier (1883), this velocity depends on the mixture's thermal diffusivity and reaction rate and the temperature of the flame zone. The flashback model further assumes that the flame is abruptly extinguished at a certain distance from the wall, which is called the quenching distance $\left(\delta_{q}\right)$. The model, which also considers the flame front to be stabilized upstream the edge of the tube prior to flashback, represents various conditions related to flame propagation within the tube. The horizontal axis represents the distance from the tube wall and the vertical axis is that of the stream wise velocity component. In this figure, lines $u_{1}, u_{2}$ and $u_{3}$ correspond to increasing flow velocities, whereas the solid line represents the local laminar flame front speed $\left(S_{L}\right)$. It should be emphasized that the flame front burning velocity is zero within the quenching region. Line $u_{2}$ indicates the situation when the flame flashback is about to occur, i.e., where the flow velocity is equal to the laminar flame front velocity, at the penetration distance. If the flow velocity is reduced (line $u_{1}$ ), the flame begins to propagate into the tube. On the other hand, when the flow velocity is increased, such as in line $u_{3}$, the flame leaves the tube and returns to the steady state downstream the tube rim. As a consequence, the critical condition for observing flashback arises when the flow velocity in the penetration distance equals the burning velocity $\left(S_{L}\right)$. The critical velocity gradient is then represented as a ratio between the laminar flame velocity and the penetration distance. It is also customary to relate the critical velocity gradient with the derivative of the flow velocity profile. Therefore, the critical velocity gradient can be expressed as (Lewis and von Elbe, 1987; Kalantari and McDonell, 2017):

$$
G_{c}=\frac{S_{L}}{\delta_{p}}=\frac{4 \bar{U}}{R}=\frac{4 \forall_{t}}{\pi R^{3}}
$$

Accordingly, the objectives of this work are to:

- Develop and build an apparatus for the study of flame flashback in laminar flows;

- Compare the measured critical flow conditions for flashback onset to existing natural gas/air and propane/air experimental results (Lewis and von Elbe, 1949).

- Experimentally determine, for mixtures of gaseous hydrocarbons (methane and propane) and air, the influence of $\mathrm{CO}_{2}$ or $\mathrm{N}_{2}$ dilution on the boundary layer flames flashback.

In what follows, the experimental apparatus used is briefly presented, including a statement of the associated uncertainties. Then are discussed the experimental results obtained for mixtures of methane, diluent $\left(\mathrm{CO}_{2}\right.$ or $\left.\mathrm{N}_{2}\right)$ and air, and also for mixtures in which commercial propane completely replaces $\mathrm{CH}_{4}$. The results' analysis adopts different representations, in order to highlight the flame flashback control parameters. Initially the results are presented using the classical flashback limit representation as a function of the total flow rate of the reactant mixture and the percentage of fuel in it. 
Then, the critical velocity gradient is studied as a function of the mixture stoichiometry. Finally, conclusions and prospects for future work are given.

\section{EXPERIMENTAL METHODOLOGY}

From the analysis of the expected fuel, air and diluent flow rate ranges, an experimental setup similar to those that may be found in the literature has been developed (Kalantari and McDonell, 2017). The experimental configuration, which is shown schematically in Fig. 2, consists of flow controllers, one for air, one for fuel and one for the diluent, and quartz tubes with different internal diameter $(D=6,8$ and $17 \mathrm{~mm}$ ) and length $L=1000 \mathrm{~mm}$, upstream of which the gases are pre-mixed. Combustion takes place at the open end of the tube and the flow rates are changed until combustion moves upstream, into the tube, which characterizes the boundary layer flashback. To this end, a flow controller is used for each gas used in the mixture. The specified flow controllers (Alicat, models MC-500SCCM, MC-5SLPM and MC-20SLPM) cover the maximum (10 SLPM) and minimum (0.1 SCCM) flow rate ranges required to perform an accurate flashback characterization. The corresponding uncertainties are $0.2 \%$ of full scale for each flow controller.

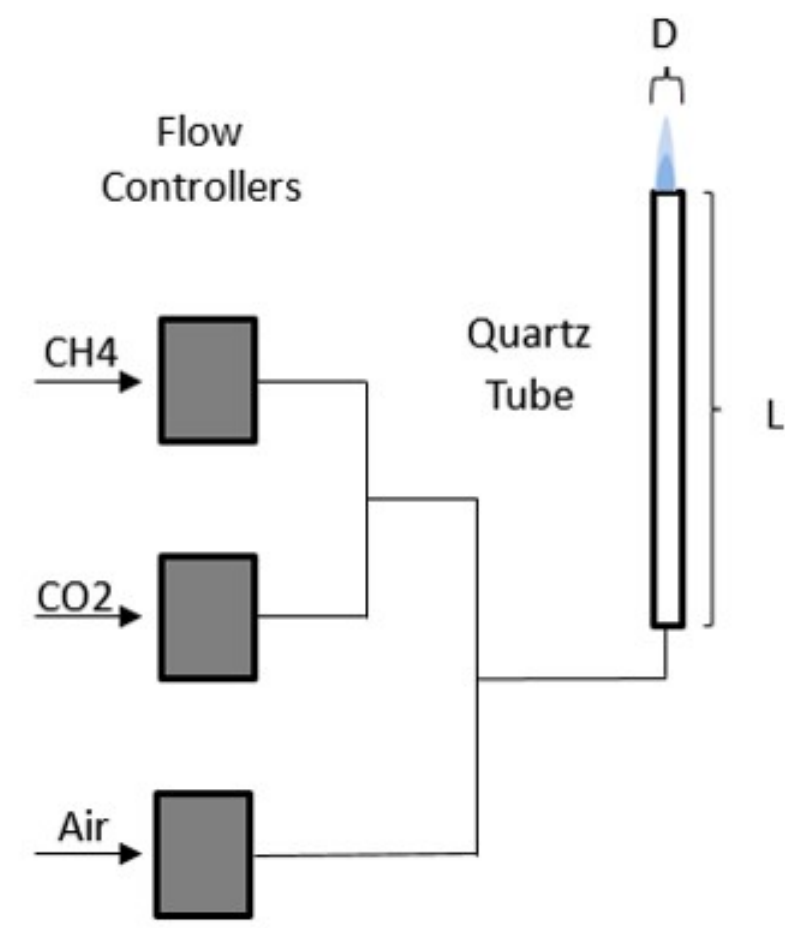

Figure 2: Experimental setup schematic model.

In order to carry out the experiments, first, without diluting the fuel with inert gas, the air flow is fixed so as to vary the fuel flow only. Then, the fuel flow is regulated until the flame flashback is observed. This procedure is repeated in order to map the flame flashback of rich, lean and stoichiometric mixtures. Then, to perform the dilution experiments, the fuel and diluent flow rates are held constant. In this way, the inert to fuel dilution ratio is guaranteed for each experimental point, whereas the air flow is varied in order to attain the critical conditions leading to the phenomenon of flame flashback. This experimental procedure is repeated at least once for each critical flow rate value.

The procedure used to determine the experimental uncertainty uses the method (ABNT and INMETRO, 2003), in which type A and type B uncertainties have been evaluated from calibration certificates of flow controllers and measurements made in the laboratory. Then, the uncertainties are calculated for the main parameters used in the experiment, such as: total flow rate, critical velocity gradient, equivalence ratio and the flow velocity. The calculated uncertainties of the equivalence ratio, the flow velocity and the critical velocity gradient are $\pm 4 \%, \pm 3 \%$ and $\pm 4 \%$, respectively.

Following the model given by Eq. (1), in order to compare the flashback propensity of the different studied mixtures, a numerical calculation of the laminar flame front speed, $S_{L}$ is made using the Ansys CHEMKIN software together with the GRI 3.0 model (Smith et al., 1999) of thermodynamics, transport and chemical reactions for methane mixtures, and the San Diego MECH model (2016-12-14) (Mechanical and Aerospace Engineering (Combustion Research) and UCSD, 2016) for propane mixtures. The choice of these mechanisms is based on the agreement with computed laminar flame speeds (Konnov et al., 2018). An equivalence ratio $(\phi)$ range is used that also encompasses the points used in the 
experimental results, i.e., from 0.55 to 1.6. Results may be compared for mixtures involving methane and propane in Tab. 1, where different flame properties are given as a function of the diluent molar and mass fractions used in the study. These properties are the computed maximum values of adiabatic flame temperature and flame speed. In this table it may be verified that, as the diluent concentration is increased, both the adiabatic flame temperature and the flame front speed decreases. This behavior is expected to directly influence the measured $G_{c}$ values, also given in this table, but which discussion is deferred to section 3.3

Table 1: Comparison between dilutions influence on maximum flame speed for mixtures of methane/ air/ diluent and propane/air/diluent.

\begin{tabular}{|c|c|c|c|c|c|c|}
\hline Fuel & Diluent & $\%$ molar & $\%$ mass & $\mathrm{S}_{L, \max }(\mathrm{cm} / \mathrm{s})$ & $\mathrm{T}_{\max }(\mathrm{K})$ & $\mathrm{G}_{c, \max }(1 / \mathrm{s})$ \\
\hline \multirow{5}{*}{$\mathrm{CH}_{4}$} & - & - & - & 38.4 & 2,236 & 462 \\
\hline & \multirow{2}{*}{$\mathrm{CO}_{2}$} & 15 & 25 & 35.4 & 2,214 & 372 \\
\hline & & 30 & 55 & 28.2 & 2,136 & 246 \\
\hline & \multirow{2}{*}{$\mathrm{N}_{2}$} & 15 & 17 & 37.2 & 2,215 & 396 \\
\hline & & 30 & 43 & 33.9 & 2,178 & 334 \\
\hline \multirow{5}{*}{$\mathrm{C}_{3} \mathrm{H}_{8}$} & - & - & - & 41.8 & 2,283 & 675 \\
\hline & \multirow{2}{*}{$\mathrm{CO}_{2}$} & 15 & 15 & 39.9 & 2,265 & 655 \\
\hline & & 25 & 25 & 38.4 & 2,252 & 575 \\
\hline & \multirow[b]{2}{*}{$\mathrm{N}_{2}$} & 25 & 17 & 40.4 & 2,265 & 627 \\
\hline & & 55 & 43 & 36.8 & 2,227 & 473 \\
\hline
\end{tabular}

It should be noted that, in addition to $\mathrm{CO}_{2}$ as a diluent, $\mathrm{N}_{2}$ is also used. This choice is motivated by the chemical nature of carbon dioxide, which, as a product of combustion, has an effect on the concentration of the burnt mixture components. This effect is well known in the case of the thermochemical balance of the combustion products of hydrocarbons and air rich mixtures, and can be explained due to the water-gas shift equation, which describes the reaction of carbon monoxide and water vapor to form carbon dioxide and hydrogen. Thus, an increase in the concentration of $\mathrm{CO}_{2}$ displaces the balance of combustion products, resulting in a greater presence of $\mathrm{H}_{2} \mathrm{O}$ and $\mathrm{CO}$. This is why $\mathrm{N}_{2}$ has been chosen for comparison purposes.

\section{RESULTS AND DISCUSSION}

This section presents the experimental results obtained for mixtures of methane, diluent $\left(\mathrm{CO}_{2}\right.$ or $\left.\mathrm{N}_{2}\right)$ and air, and also for mixtures in which commercial propane completely replaces $\mathrm{CH}_{4}$. The results analysis adopts different representations, in order to highlight the parameters that control the flame flashback. Initially the results are presented using the classical flashback limit representation as a function of the total flow rate of the reactant mixture and the percentage of fuel in it, for various tube diameters. Then, the critical velocity gradient is given as a function of the combustible mixture equivalence ratio. Figure 3 illustrates the flames studied in three typical situations:

left A flame corresponding to a lean mixture, stabilized outside the tube, for a velocity gradient value larger than the critical one. The surface of this flame is smooth and its upper end is closed, which is characteristic of flames with a Lewis number close to one.

center A rich propane and air flame, stabilized outside the tube, for a velocity gradient value far from the critical, also. This flame is characterized, on its internal surface, by undulations that reflect the intrinsic instabilities (Law, 2006). Downstream of this surface, a plume is observed, in which the excess of $\mathrm{CO}$ and $\mathrm{H}_{2}$ present is oxidized the ambient air $\mathrm{O}_{2}$.

right A flame that propagates in a rich mixture, representative of the moment when the value of the velocity gradient becomes smaller than the critical value, and the flame penetrates the quartz tube. When compared to the previous situations, it is clear that this flame is not axisymmetric, presenting at this transient moment a three-dimensional surface.

\subsection{Flashback limits for different tube diameters}

The first experiments have been performed for mixtures of methane/air in order to validate the obtained results by comparison with those given in the literature. Accordingly, Fig. 4a shows the measured flame flashback limits as a function of the combustible gases flow rate and fuel molar percentage, for methane/air mixtures. In this figure each symbol represents the measured flame flashback boundary. The different symbols represent the three tube diameters used, the leftmost being the one corresponding to the smallest diameter $(6 \mathrm{~mm})$ and the rightmost curve corresponding to the 


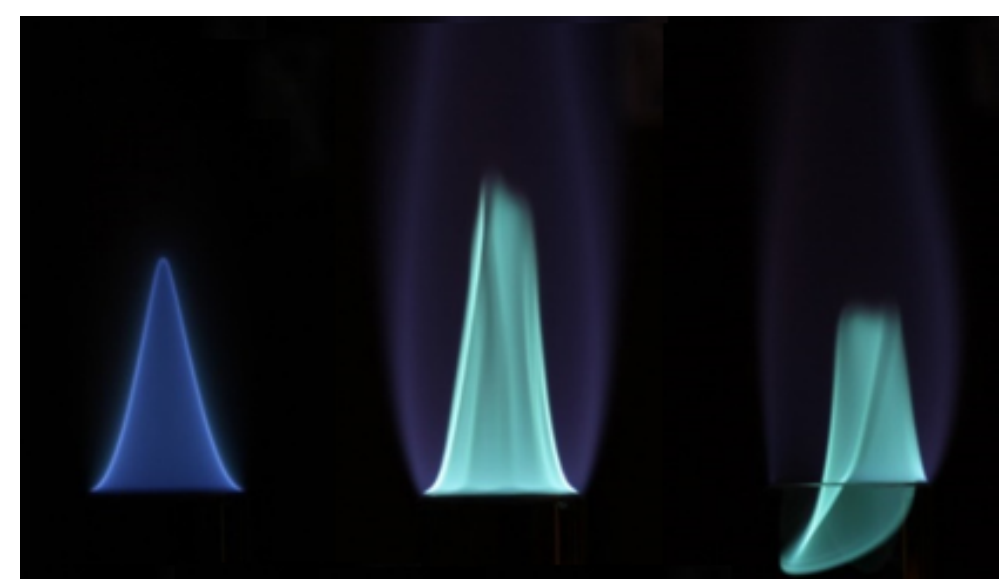

Figure 3: Flames of propane / air mixtures obtained experimentally in a $17 \mathrm{~mm}$ diameter tube. Leftmost: lean mixture, flame stabilized outside the tube, Center: rich mixture, flame stabilized outside the tube, Rightmost: rich mixture, flame at the flashback critical velocity gradient.

largest diameter $(17 \mathrm{~mm})$. Flame flashback always occurs inside each zone delimited by these symbols, therefore, it may be verified that, as the tube diameter increases, the absolute propensity zone for flame flashback to occur decreases. In the particular case of the $17 \mathrm{~mm}$ diameter tube, the maximum flow rate is in the order of $215 \mathrm{~cm}^{3} / \mathrm{s}$ for $9.3 \%$ of fuel. As this percentage increases or decreases, the total flow rate decreases. For instance, at the point where there is $11.89 \%$ of fuel, the critical flow rate is $75.67 \mathrm{~cm}^{3} / \mathrm{s}$ and, at the point where $6.76 \%$ of fuel, the critical flow rate is $71.5 \mathrm{~cm}^{3} / \mathrm{s}$. At the neighborhood of stoichiometry, the maximum total flow rate for which the flame flashback is observed is found to occur and, as the mixture composition moves away from the stoichiometry $(9.51 \%$, since methane 2.0 is used) these critical total flow rates decrease.

Figure 4a also validates the experimental methodology used by comparison with the data found in the literature (Lewis and von Elbe, 1949), which are shown as the solid lines in Fig. 4a. The main difference between these results and the small displacement on the vertical axis is due to the composition of the gases used. Indeed, while in the literature natural gas of unknown composition is used (stoichiometry presumably $\approx 9 \%$ ). This slight difference could explain the observed displacement of the vertical axis.

\subsection{Carbon dioxide dilution influence}

Figures $4 \mathrm{~b}$ and $4 \mathrm{c}$ show, in a representation identical to Fig. $4 \mathrm{a}$, the flame flashback limits for mixtures considering $\mathrm{CO}_{2}$ and $\mathrm{N}_{2}$ dilution, which are given in Tab. 1. These figures exhibit, respectively, the results obtained for methane/air and propane/air mixtures for a single tube diameter, $17 \mathrm{~mm}$. From these results, it may be observed that as the percentage of diluent in the fuel increases, the region bounded by the symbols is reduced, thus leading to a reduced flashback propensity.

Similarly to what has been observed when analyzing the results given in Fig. 4a, the maximum flow rate leading to flashback occurs in the stoichiometric region and as the mixture composition increases or decreases from it the total flow rate for which the flame flashback is observed decreases. As dilution is increased, the critical flow rate for the same percentage of fuel decreases. More specifically, concerning the methane/air/diluent results, the undiluted mixture, close to stoichiometry $\left(9.3 \%\right.$ fuel), has a critical flow rate of $215 \mathrm{~cm}^{3} / \mathrm{s}$, whereas a mixture with $10 \%$ dilution by $\mathrm{CO}_{2}$ and $9.43 \%$ of fuel is characterized by a critical flashback flow rate of $176.86 \mathrm{~cm}^{3} / \mathrm{s}$. For the propane/air/diluent mixtures, at the stoichiometry region, the critical flow rate is of the order of $350 \mathrm{~cm}^{3} / \mathrm{s}$ without dilution and of the order of $250 \mathrm{~cm}^{3} / \mathrm{s}$ with $25 \% \mathrm{CO}_{2}$ dilution.

The comparative analysis of the effect of $\mathrm{CO}_{2}$ and $\mathrm{N}_{2}$ dilution is deferred to the following section.

\subsection{Critical velocity gradient: $\mathrm{CO}_{2}$ and $\mathrm{N}_{2}$ dilution influence}

Another way to represent the flame flashback is through the critical velocity gradient [Eq. (1)]. Figure 5 shows the critical velocity gradient for methane/air mixtures, as a function of the equivalence ratio, for different tube diameter values. This figure is an adaptation of the literature, with the experimental data obtained in the present work (colored) superimposed on the literature data (black) (Lewis and von Elbe, 1949). Figure 5 shows that expressing the flame flashback limits in the characteristic form of the critical velocity gradient has the effect of collapsing the data for different tube diameters in a single "curve". A notable difference between the experimental data and literature results is a slight displacement of the vertical axis, which could be attributed to the composition of the fuel. In the literature, natural gas of unknown composition and stoichiometry of $9 \%$ was used, whereas in the present work, methane 2.0, with stoichiometry of $9.51 \%$, is the fuel. In Fig. 5, the region enclosed by the symbols is the region within which the flashback occurs. The maximum 




(a) Methane/air mixtures in 6,8 and $17 \mathrm{~mm}$ diameter tubes. Experimental points are represented by the symbols and literature results (Lewis and von Elbe, 1949) represented by the solid lines.

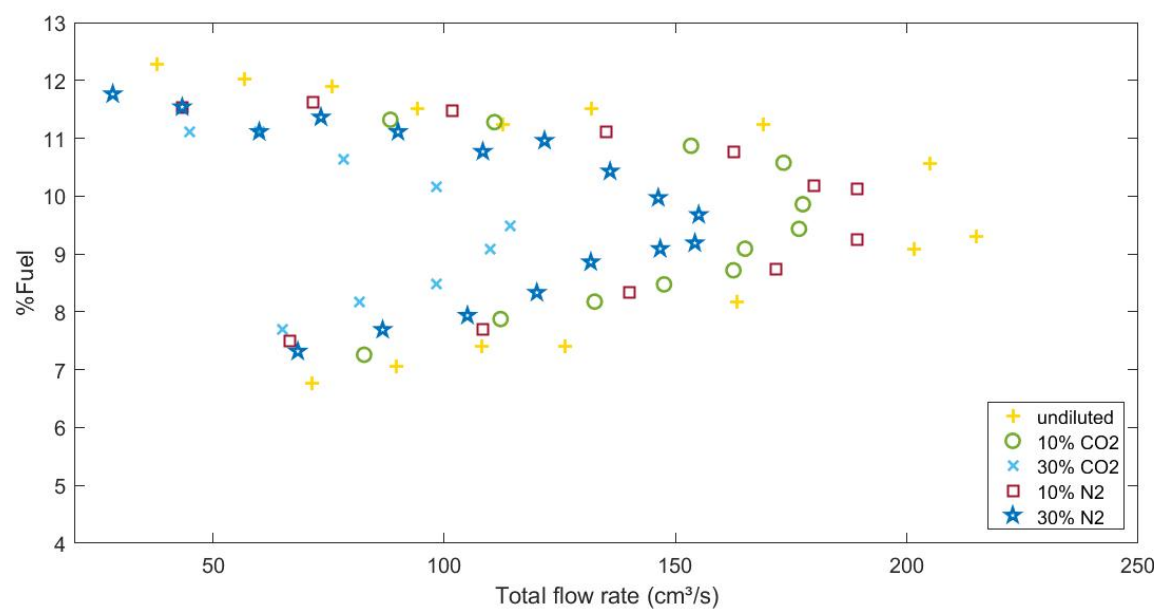

(b) Methane/air/diluent mixtures in a $17 \mathrm{~mm}$ diameter tube, indicated are the fuel diluent percentages.

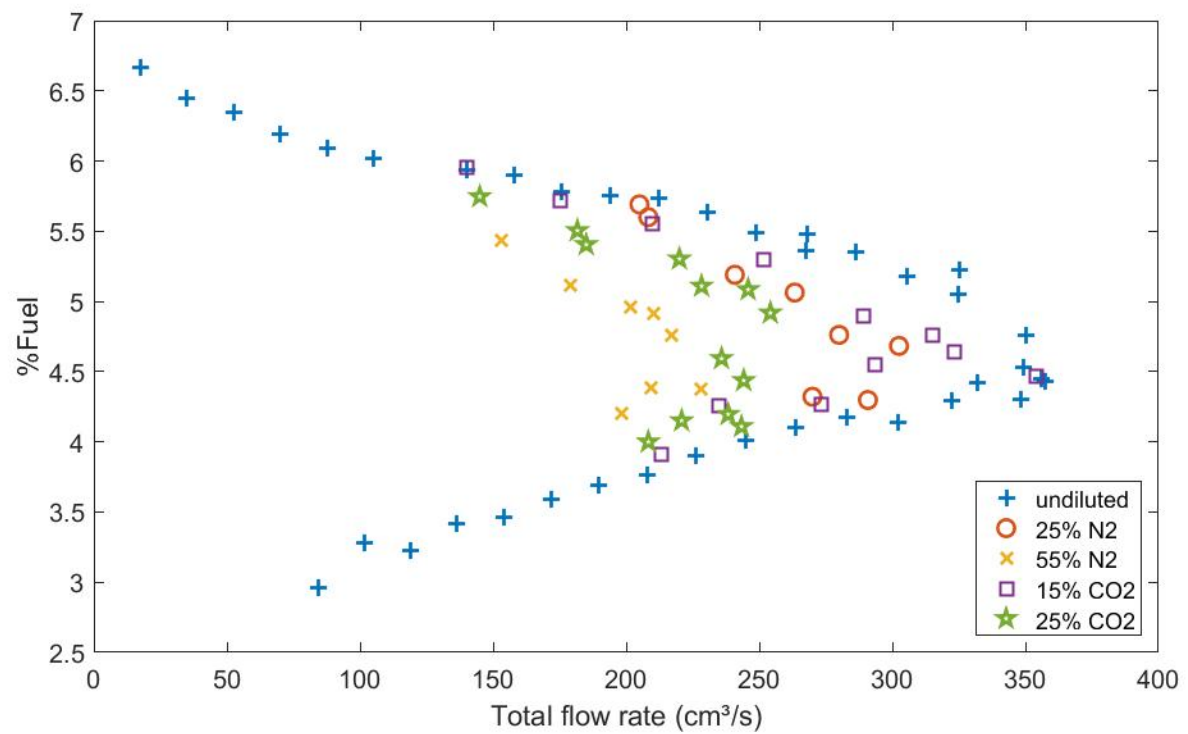

(c) Propane/air/diluent mixtures in a $17 \mathrm{~mm}$ diameter tube, indicated are the fuel diluent percentages.

Figure 4: Flame flashback limits as a function of the total flow rate and fuel percentage. 


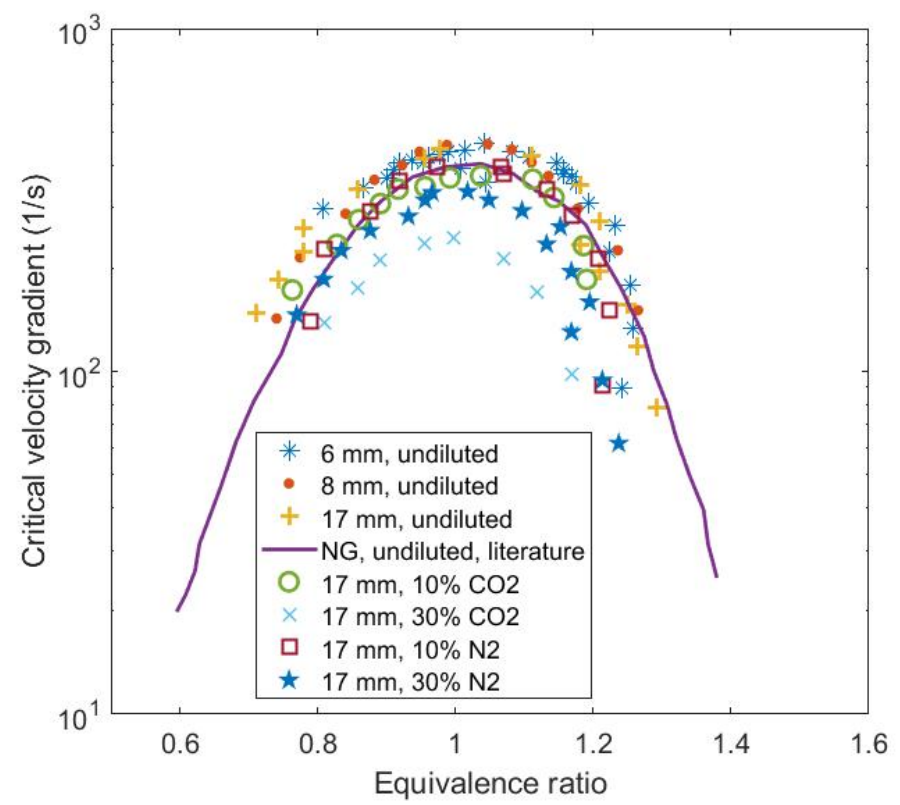

Figure 5: Critical velocity gradient as a function of the equivalence ratio for methane/air/diluent mixtures, indicated are the fuel diluent percentages. Comparison with literature results (Lewis and von Elbe, 1949), no dilution, 6, 8 and 17 mm diameter tubes. Diluted: $17 \mathrm{~mm}$ diameter tube only.

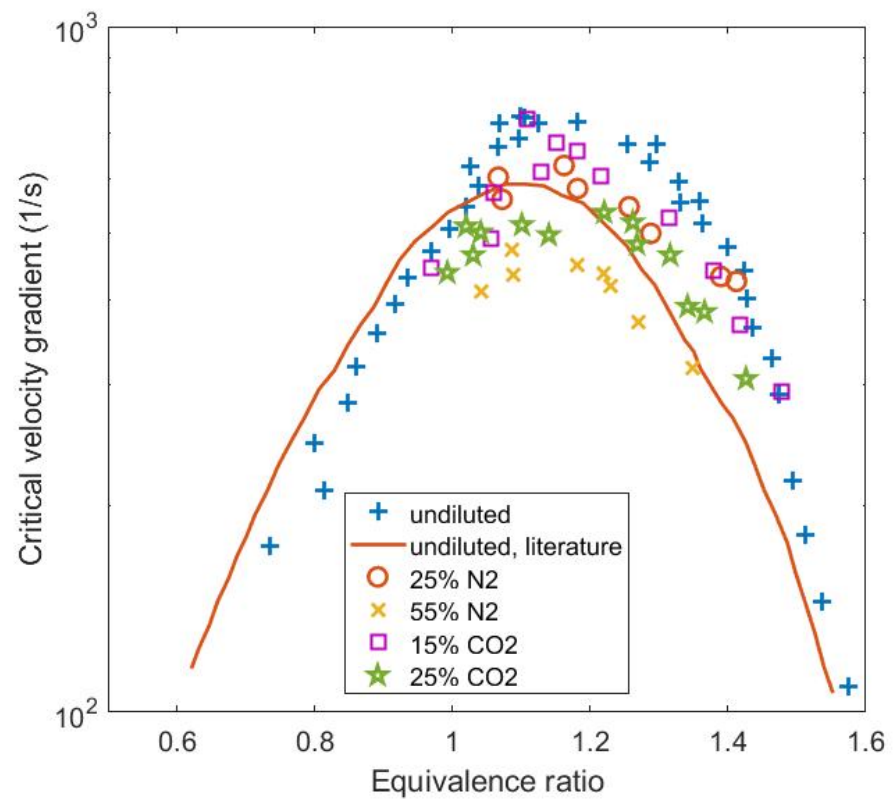

Figure 6: Comparison between the measured critical velocity gradient and literature results (Lewis and von Elbe, 1949) for propane/air/diluent mixtures in the $17 \mathrm{~mm}$ diameter tube, indicated are the fuel diluent percentages.

value of the critical velocity gradient $\left(\approx 445 \mathrm{~s}^{-1}\right)$ occurs in the stoichiometry region due to the higher flame speeds and, as the equivalence ratio is either decreased or increased, the critical velocity gradient decreases.

In order to evidence the fuel dilution influence, Fig. 5 also shows the critical velocity gradient for methane/air/diluent mixtures, whereas in Fig. 6 the results corresponding to propane/air mixtures are depicted. It is observed that as the dilution concentration increases the region bounded by the symbols - the flashback zone - is reduced, thus, reducing critical velocity gradient that leads to flame flashback for both fuels. It is also possible to observe that the maximum values of the critical velocity gradient for diluted mixtures also lie at the stoichiometry region. Fuel lean or fuel rich diluted mixtures also exhibit a reduced value of the critical velocity gradient

As the critical velocity gradient is directly related to the flame propagating speed [Eq. (1)], the influence of the fuel dilution on $S_{L, \max }$ and on $G_{c, \max }$ is shown in Table 1. Indeed, for methane/air/diluent mixtures, the maximum value 
of the critical velocity gradient goes from $462 \mathrm{~s}^{-1}$ (no dilution) to $246 \mathrm{~s}^{-1}\left(30 \% \mathrm{CO}_{2}\right.$ dilution) and $334 \mathrm{~s}^{-1}\left(30 \% \mathrm{~N}_{2}\right.$ dilution). For propane/air/diluent mixtures, a similar behavior is shown: $675 \mathrm{~s}^{-1}$ with no dilution then a reduction is observed as dilution is increased $\left(575 \mathrm{~s}^{-1}\right.$ for $25 \%$ of $\mathrm{CO}_{2}$ and $473 \mathrm{~s}^{-1}$ for $55 \%$ of $\left.\mathrm{N}_{2}\right)$. Thus, the dependence of the critical velocity gradient on the laminar flame front speed shown in Eq. (1) and in Table 1, explains the reduction of the measured $G_{c, \max }$ values, since the values of $S_{L, \max }$ are reduced as the diluent concentration is increased.

\section{CLOSING REMARKS}

Flame flashback experiments were carried out on the 6,8 and $17 \mathrm{~mm}$ diameter tubes (17 mm including dilution). In particular, a critical velocity gradient was determined for $\mathrm{CH}_{4}$ /air and propane/air mixtures with $\mathrm{CO}_{2}$-diluted fuel $(0,10$ and $30 \%)$. For comparison purposes, measurements were also performed on $\mathrm{CH}_{4} /$ diluted by $\mathrm{N}_{2}$ mixtures. For both diluent chemical compounds $\left(\mathrm{CO}_{2}\right.$ and $\left.\mathrm{N}_{2}\right)$, a reduction in the maximum value of the critical velocity gradient with increasing dilution was found. The equivalence ratio range that delimits the flashback limits was also found to be reduced by increasing the dilution of fuel by $\mathrm{CO}_{2}$ or $\mathrm{N}_{2}$. The observed critical velocity gradient behavior was associated to the corresponding reduction in the laminar flame front speed with dilution by a chemically inert species.

\section{ACKNOWLEDGEMENTS}

This work was supported by Petrobras contract no. 5900.0111688.19.9 under the technical monitoring of Dr. P. R. Pagot. This work was performed while L.F. Figueira da Silva was on leave from the Institut Pprime (CNRS, France). Support was also received from Conselho Nacional de Desenvolvimento Científico e Tecnológico (CNPq, Brazil) under the Research Grant No. 304444/2018-9. This study was financed in part by the Coordenação de Aperfeiçoamento de Pessoal de Nível Superior - Brasil (CAPES) - Finance Code 001.

\section{REFERENCES}

ABNT and INMETRO, 2003. Guia para a Expressão da Incerteza de Medição. SAFIRA Comunicação.

ANP, 2020. "Estudo sobre o aproveitamento do gás natural do pré-sal". http://www .anp.gov.br/arquivos/estudos/aproveitamento-gn-pre-sal.pdf.

Kalantari, A. and McDonell, V., 2017. "Boundary layer flashback of non-swirling premixed flames: Mechanisms, fundamental research, and recent advances". Progress in Energy and Combustion Science, Vol. 61, pp. 249 - 292. ISSN 0360-1285. doi:https://doi.org/10.1016/j.pecs.2017.03.001. URL http://www.sciencedirect.com/science/article/pii/S0360128516301253.

Konnov, A.A., Mohammad, A., Kishore, V.R., Kim, N.I., Prathap, C. and Kumar, S., 2018. "A comprehensive review of measurements and data analysis of laminar burning velocities for various fuel+air mixtures". Progress in Energy and Combustion Science, Vol. 68, pp. 197 - 267. ISSN 0360-1285. doi:https://doi.org/10.1016/j.pecs.2018.05.003. URL http://www.sciencedirect.com/science/article/pii/S0360128517301417.

Law, C.K., 2006. Combustion physics. Cambridge University Press. ISBN $9780511754517 . \quad$ doi: $10.1017 / \mathrm{CBO} 9780511754517$.

Lewis, B. and von Elbe, G., 1949. "Structure and stability of burner flames". Transactions of the Faraday Society, Vol. 45, No. 9, pp. 781-794. doi:10.1039/tf9494500781.

Lewis, B. and von Elbe, G., 1987. Combustion, Flames and Explosions of Gases. Academic Press, New York, 3rd edition.

Mallard, E. and Le Chatelier, H., 1883. "Combustion of explosive gas mixtures". Annals of Mines.

Mechanical and Aerospace Engineering (Combustion Research) and UCSD, 2016. "Chemical-Kinetic Mechanisms for Combustion Applications". URL http://combustion.ucsd.edu.

Smith, G.P., Golden, D.M., Frenklach, M., Moriarty, N.W., Eiteneer, B., Goldenberg, M., Bowman, C.T., Hanson, R.K., Song, S., Gardiner, W.C., Lissianski, V.V. and Qin, Z., 1999. "GRI-Mech 3.0”. URL http://www.me.berkeley.edu/gri_mech/.

\section{RESPONSIBILITY NOTICE}

The authors are solely responsible for the printed material included in this paper. 